\title{
"São pessoas com sotaque estrangeiro": sobre visões de educadores na fronteira
}

\author{
"Son personas con acento extranjero": sobre visiones de educadores en \\ la frontera
"They are people with foreign accents": about visions of educators at the border

\section{Laura Janaina Dias Amato ${ }^{1}$}

\begin{abstract}
Resumo
O presente trabalho é resultado do projeto de pesquisa "Construção crítica do imaginário trinacional" que visa analisar a construção discursiva sobre a região trinacional, constituída pelas cidades de Foz do Iguaçu - Ciudad del Este - Puerto Iguazu a partir de ações realizadas em ambientes educacionais formais. Tendo como principal base epistemológica os estudos críticos da linguagem, partindo de um ponto de vista ontológico, esta perspectiva parte do entendimento de que a realidade não é algo que possa ser concretamente capturada e conhecida definitivamente. Aqui apresentaremos uma discussão com base em Maturana (2001; 2002) para tentar compreender as respostas de um questionário aplicado em um grupo de professores que realizaram um curso de formação continuada com premissas de uma pedagogia intercultural. Pretende-se, assim, dar visibilidade a uma realidade que é construída a partir do olhar do observador [membros da comunidade escolar de Foz do Iguaçu] e pela linguagem, sendo ela determinada histórica, social, política, ideológica e discursivamente; e assim analisar e compreender como as relações estabelecidas no meio escolar são transmitidas e constituídas, podendo então refletir sobre as relações construídas inter e transculturalmente.
\end{abstract}

Palavras-Chave: ensino intercultural; fronteira e território; estudos críticos de linguagem.

\section{Resumen}

El presente trabajo es el resultado del proyecto de investigación "Construcción crítica del imaginario trinacional" que busca analizar la construcción discursiva sobre la región trinacional, constituida por las ciudades de Foz do Iguaçu - Ciudad del Este - Puerto Iguazú a partir de acciones realizadas en ambientes educativos formales. Con base epistemológica de los estudios críticos del lenguaje, partiendo desde un punto de vista ontológico, esta perspectiva parte del entendimiento de que la realidad no es algo que pueda ser concretamente capturada y conocida definitivamente. Aquí presentamos una discusión basada en Maturana (2001; 2002) para tratar de comprender las respuestas de un cuestionario aplicado en un grupo de profesores que realizaron un curso de formación continuada con premisas de una pedagogía intercultural. Se pretende, así, dar visibilidad a una realidad que se construye a partir de la mirada del observador [miembros de la comunidad escolar de Foz do Iguaçu] y por el lenguaje, siendo ella determinada histórica, social, política, ideológica y discursivamente; $Y$ así analizar y comprender cómo las relaciones establecidas en el medio escolar son transmitidas y constituidas, pudiendo entonces reflexionar sobre las relaciones construidas inter $y$ transculturalmente.

Palabras claves: enseñanza intercultural; frontera y território; estudios críticos del lenguaje.

\section{Abstract}

This work is the result of the research project "Critical construction of the trinational imaginary", which aims to analyze the discursive construction of the trinational region, constituted by the cities of Foz do Iguaçu-Ciudad

\footnotetext{
${ }^{1}$ Doutora em Letras; Universidade Federal da Integração Latino-Americana; Foz do Iguaçu, Paraná, Brasil; laura.amato@unila.edu.br. Trabalho apresentado no I Seminário Latino-Americano de Estudos em Cultura SEMLACult, Foz do Iguaçu/PR, Brasil, 2017.
} 
del Este - Puerto Iguazu from actions carried out in formal educational environments . This main epistemological basis is the critical studies of language, starting from an ontological point of view, this perspective starts from the understanding that reality is not something that can be concretely captured and definitely known. Here we present a discussion based on Maturana (2001; 2002) to try to understand the answers of a questionnaire applied in a group of teachers who carried out a course of continuous formation with premises of an intercultural pedagogy. It is intended, therefore, to give visibility to a reality that is constructed from the observer's gaze [members of the school community of Foz do Iguaçu] and language, being determined historical, social, political, ideological and discursively; And thus to analyze and to understand how the relations established in the school environment are transmitted and constituted, being able to reflect on the relationships built inter and transculturally

Keywords: intercultural education; frontier and territory; critical language studies.

\section{Introdução}

O Brasil possui uma das maiores fronteiras terrestre do mundo, com aproximadamente 15.700 km (Goes Filho, 2013), e fazendo divisa com 10 países da América do Sul. Somandose a isso, temos 32 cidades-gêmeas, que segundo o artigo $1^{\circ}$ da Portaria 213 , do Ministério da Integração Nacional, de 19 de julho de 2016, são "municípios cortados pela linha de fronteira, seja essa seca ou fluvial, articulada ou não por obra de infraestrutura, que apresentem grande potencial de integração econômica e cultural, (...)" e que incidem diretamente no desenvolvimento regional e nos direitos dos cidadãos que lá habitam. Além das cidadesgêmeas, nesta imensidão fronteiriça, temos ainda o privilégio de termos 10 tríplices fronteiras, ou seja, em 10 localidades diferentes o Brasil faz fronteira com dois países ao mesmo tempo. Foz do Iguaçu, no Estado do Paraná, é uma dessas tríplices fronteiras, fazendo divisa com Argentina e Paraguai.

Conformes dados da página da prefeitura, em 2014, já eram registradas 81 etnias diferentes na cidade de Foz de Iguaçu; e atualmente é o terceiro destino turístico mais visitado do país pelos estrangeiros (PMFI, 2017). Tanta diversidade e tanto fluxo de pessoas faz desta tríplice fronteira um lugar único e diverso. Características estas visíveis ao caminharmos em certas localidades da cidade: perto da Mesquita encontramos muitas padarias com produtos árabes, em toda a cidade vemos o tráfego de automóveis com placas argentinas e paraguaias, em semáforos há sempre vendedores - paraguaios na maioria das vezes - de chipa e alho. Esse cotidiano plural e diverso afeta a população de alguma forma: seu consumo, sua identidade como cidade, suas políticas, sua forma de ver e lidar com si e com o outro. Partindo desta perspectiva propusemos investigar a visão de educadores da rede municipal de ensino em relação a habitar na fronteira e a relação que possuem com os habitantes dos países vizinhos. O objetivo era averiguar quais posicionamentos poderiam ser repassados $-\mathrm{e}$ até perpetuados - pelos educadores nas séries iniciais. Temos como premissa básica que as 
crianças, na maioria das vezes, entra no ambiente educacional com pouco ou nenhum (pré) conhecimento sobre os paraguaios e argentinos e na escola apre(e)ndem visões sobre os moradores dos países vizinhos; visões estas que podem ser preconceituosas, com tendência a neutralizar e invisibilizar o outro.

\section{Da pesquisa}

A pesquisa iniciou-se em meados de 2015 como parte do projeto de extensão da Universidade Federal Latino-Americana (UNILA) intitulado "Fronteira Intercultural". Uma das propostas do projeto era sensibilizar alunos da rede municipal de ensino para a cultura latino-americana em língua espanhola. A escola na qual o projeto estava integrado era a Adele Zanotto Scalco, conhecida por receber o Programa Escolas Interculturais de Fronteira (PEIF) desde 2005. O PEIF é um programa do governo federal, aprovado no Mercosul Educacional e em parceria com os Ministérios da Educação dos países-membros do Mercosul. Entre as ações do PEIF está o chamado cruce, quando um professor da escola-parceira na Argentina, no caso a Escuela Bilíngüe n², vai à escola-parceira no Brasil, no caso a Adele Zanotto, e ministra aula em espanhol para as crianças, enquanto o professor brasileiro ministra aulas em português para as crianças argentinas. O objetivo principal não é o aprendizado da língua, mas na e com a língua adicional ${ }^{2}$.

A escolha da escola não foi mero acaso, mas foi com o objetivo de auxiliar o cumprimento de um dos objetivos do PEIF, que é tornar a ESCOLA intercultural. Tal ação se deve por averiguarmos que os tamanhos das escolas-parceiras eram muito diferentes, pois enquanto na escola argentina todas turmas eram atendidas com o número de professoras brasileiras liberadas para atuarem no programa, o mesmo não acontecia na escola brasileira. Com o mesmo quantitativo de professores atuantes no programa, ou seja, os que realizam o cruce, a escola brasileira não tinha metade de turmas com aulas em língua espanhola. Desta forma, na escola Adele Zanotto, podíamos dizer que o PEIF se limitava a algumas turmas e não a escola inteira. Desta forma, o projeto Fronteira Intercultural veio minimizar essa diferença, atuando nas turmas que não recebiam os professores argentinos e ensinando, na língua espanhola, aspectos da cultura latino-americana.

\footnotetext{
${ }^{2}$ Conforme Jordão (2014), língua adicional é determinada pelo ambiente do aprendiz, desta forma, em contextos plurilíngues fronteiriços, nos quais a circulação de populações migrantes é grande, podemos definir que na região da tríplice fronteira, o ensino deve ser voltado para o conceito de língua adicional.
} 
Junto à atividade com as crianças foi desenvolvido um curso de formação permanente para os professores da escola para trabalhar aspectos relacionados a uma Pedagogia Intercultural. O curso, ministrado em 2016, foi aberto para professores das escolas da região, principalmente para quem recebia alunos estrangeiros. Devido a demanda foi oferecido novas oficinas do curso em 2017. A pesquisa então centra-se nos professores que tiveram interesse em participar do curso de formação sobre Pedagogia Intercultural, desta forma, acreditamos que tais sujeitos estão abertos para discussões relacionadas a um ensino crítico e transcultural.

Em seguida apresentaremos brevemente alguns aspectos teóricos relevantes para a pesquisa e análise dos questionários.

\title{
2.1. Do observar
}

Segundo Maturana (2001, p. 160), "ver é uma maneira particular de operar como um sistema neuronal fechado, que é componente de um organismo em um domínio de acoplamento estrutural do organismo", assim, nosso sistema nervoso opera por meio de correlações internas na experiência, ou seja, determinado estruturalmente, desta forma o meio não estabelece a priori as mudanças, apenas as desencadeia-as. Segundo o autor (op.cit., p. 162)

\begin{abstract}
Como observadores, temos acesso ao sistema nervoso e à estrutura do seu meio, o que nos permite descrever a conduta do organismo como produto do operar do sistema nervoso com representações do meio, ou como expressão de algum processo intencional ou direcionado a uma meta. Mas tais descrições não refletem a operação do sistema nervoso em si e, portanto, sua utilidade para nós é de caráter somente comunicativo, não tendo valor explicativo científico.
\end{abstract}

Conforme Maturana (2001; 2002), nossa estrutura biológica não nos possibilita tecer referências a uma realidade externa e independente de nós, por isso, o autor defende que o observar está necessariamente vinculado à linguagem, pois os observadores só reconhecem e aceitam formulações feitas na práxis de viver na linguagem e aceita pelos critérios estabelecidos pelos pares. Sendo o nosso observar determinado pela e através da linguagem, Maturana (2002, p.253) aponta a existência de "muitas realidades explicativas diferentes, igualmente legítimas, mas não igualmente desejáveis".

\subsection{Do linguajear}

Como observadores somos capazes de conhecer, entender e transformar o meio. Segundo Maturana (2001, p. 174) somente através da linguagem isso é possível, pois 
A linguagem nunca foi inventada por um sujeito isolado na apreensão de um mundo externo e, portanto, não pode ser usada como ferramenta para revelar um tal mundo. Ao contrário, é dentro do linguajar mesmo que o ato de conhecer, na coordenação comportamental que é a linguagem, produz um mundo. Realizamos a nós mesmos em mútuo acoplamento linguístico, não porque a linguagem nos permita dizer o que somos, mas porque somos na linguagem, num contínuo existir nos mundos linguísticos e semânticos que produzimos com os outros. Encontramos a nós mesmos nesse acoplamento, não como a origem de uma referência, nem em referência a uma origem, mas sim em contínua transformação no vir-a-ser do mundo linguístico que construímos com os outros seres humanos. (grifo nosso)

Assim, só existimos dentro da linguagem, ou seja, somos seres linguajantes que constrói as realidades na, dentro e pela linguagem, pois somos seres que trabalham com coordenação de condutas. Desta forma aprendemos desde nossa tenra infância a responder coordenação de condutas de outros seres humanos e assim nos transformamos, inclusive fisiologicamente, como afirmam Matura e Verden-Zöllner (2011, p.238). Tal ação só acontece dentro da linguagem, do linguajear inerente do ser humano.

Vaz (2008, p.63) afirma que somos seres do conversar. Para ele

O conversar é uma fusão do linguagear (sic) que é essa coordenação de coordenação de condutas, com o emocionar. As emoções são estados do corpo. Chego em casa depois de um engarrafamento de uma hora e meia gritando com o cachorro, empurrando a cadeira e minha mulher diz: "Você nem me beijou?". Eu respondo: "Ah, eu vou me mudar dessa cidade", porque nesse estado emocional eu não consigo beijar ninguém. Quer dizer, as emoções são estados do corpo que delimitam os domínios de ação. Então, ao coordenar condutas com outros seres humanos, eu gero emoções, vivo emoções, e vou nessa cadeia de coordenações com emoções. E vou conversando. E quem não conversa não é humano. Isso lembra um pouco o Abelardo Chacrinha, não é? — que dizia: "Quem não se comunica, se estrumbica". Mas, para Maturana, a comunicação não existe; o que existe é essa coordenação de condutas. E, se não houver um acoplamento estrutural entre os parceiros, não acontece nada.

E a partir dessas coordenações de condutas buscamos nos relacionar e construir espaços e identidades e realidades tangíveis. E é como seres linguajantes que coordenamos condutas, modos de ser, agir e pensar.

\subsection{Do território}

HAESBART (1999) define território como um local repleto de disputas simbólicas, não delimitado geopoliticamente, mas socialmente. Segundo o autor (op. cit., p. 7)

[...] o território pode veicular poderes simbólicos de múltiplas faces, ora reforçando a segregação, ora viabilizando uma dinâmica de convívio ou de ativação de múltiplas identidades. Eis aí um armadilha e uma poderosa fonte de liberdade. Conforme os grupos e classes sociais pode-se optar por um retorno às identidades monolíticas e fechadas ou por uma abertura para as 'identidades dinâmicas' vinculadas à extrema mobilidade do nosso tempo. 
Desta forma, todo território possui sua própria identidade, chamada por Haesbart (1999) de identidade social. Esta identidade, que é territorial, fundamenta-se nas estruturas de um território fixado ou simbólico.

Quando Oliveira (2012) afirma que a fronteira não tem uma identidade própria, ela parte do princípio que a tríplice fronteira não é um território, mas um grupo de cidades e países delimitados por uma fronteira física e política. Aqui vemos a região citada como um grande território, no qual várias disputas simbólicas de poder, na concepção foucaultiana, circulam e se reconfiguram. Disputas essas entre grupos sociais, étnicos, nacionais, de gênero, entre outros, que se mesclam entre si marcando específicas relações de poder. Como exemplo podemos ver a foto abaixo:

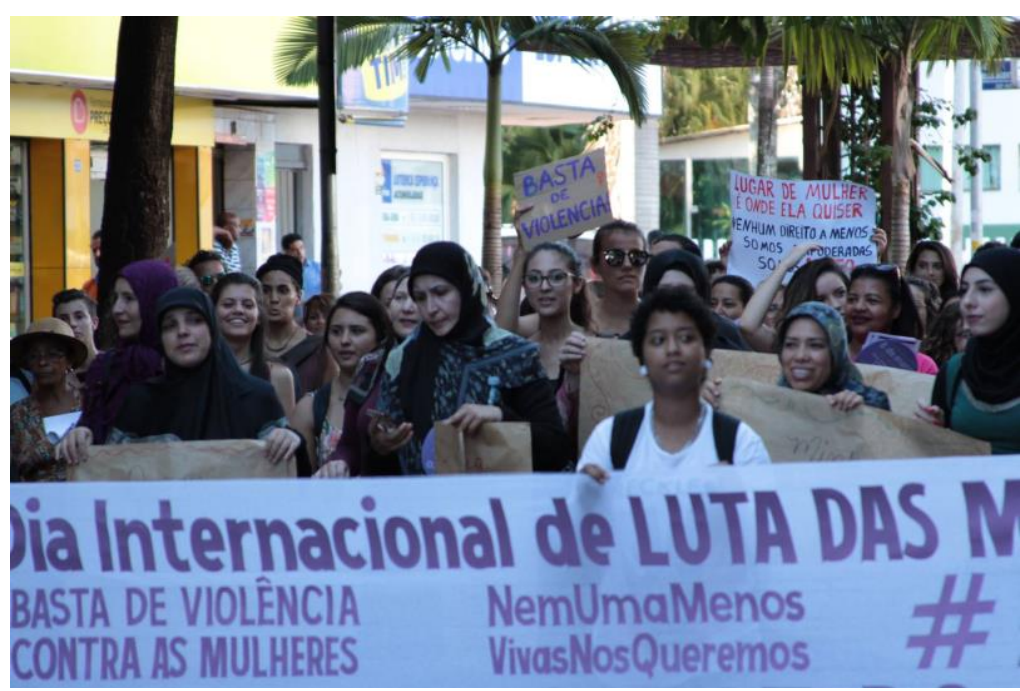

Figura 1 - Marcha do Dia Internacional das Mulheres em Foz do Iguaçu, 08.03.17

Fonte: acervo pessoal de Michele Dacas

Nesta foto mulheres se unem em torno de uma causa comum: violência contra as mulheres, demarcando um território e uma identidade. Essas mesmas mulheres podem (e pertencem) a outros grupos identitários - territorializados - que possuem outras causas, como a religiosa, por exemplo. Assim, vemos que o território não é formado pelo conjunto de seus indivíduos, mas da identidade que o compõe.

Considerando o espaço escolar como um território, no qual identidades são configuradas e negociadas, podemos observar que o modo de ver e observar são heterotópicos e linguajeantes, o que leva a constantes crises, pois entra em confronto com normativas e valores estáticos e limitadores. Vemos que enquanto o espaço escolar é constituído pelos seus sujeitos como um território, a legalidade curricular e institucional o determinam como um 
lócus com fronteiras físicas (muros e cercas) e políticas (só entra e fica quem se submete ao sistema e norma da legislação brasileira). Desta forma, ao mesmo tempo em que há o discurso da manutenção e da normalidade, há também o discurso de celebração da diversidade. Assim, as múltiplas territorialidades em disputa na região da tríplice fronteira, encontra seu microuniverso refletido no espaço escolar.

\subsection{Do inter- e transcultural}

Conforme Guilherme e Dietz (2014, p.30) termos como multiculturalismo, interculturalidade e transculturalidade possuem diferentes níveis de significado e uso, que são claramente identificados nos diferentes contextos históricos, culturais e acadêmicos. Sendo os termos polêmicos e polisemânticos, os autores optam por analisar esses três conceitos a partir de três eixos paradigmáticos. Eles analisam sob o viés da desigualdade, da diferença e da diversidade. A figura abaixo resume as implicações conceituais dos três eixos

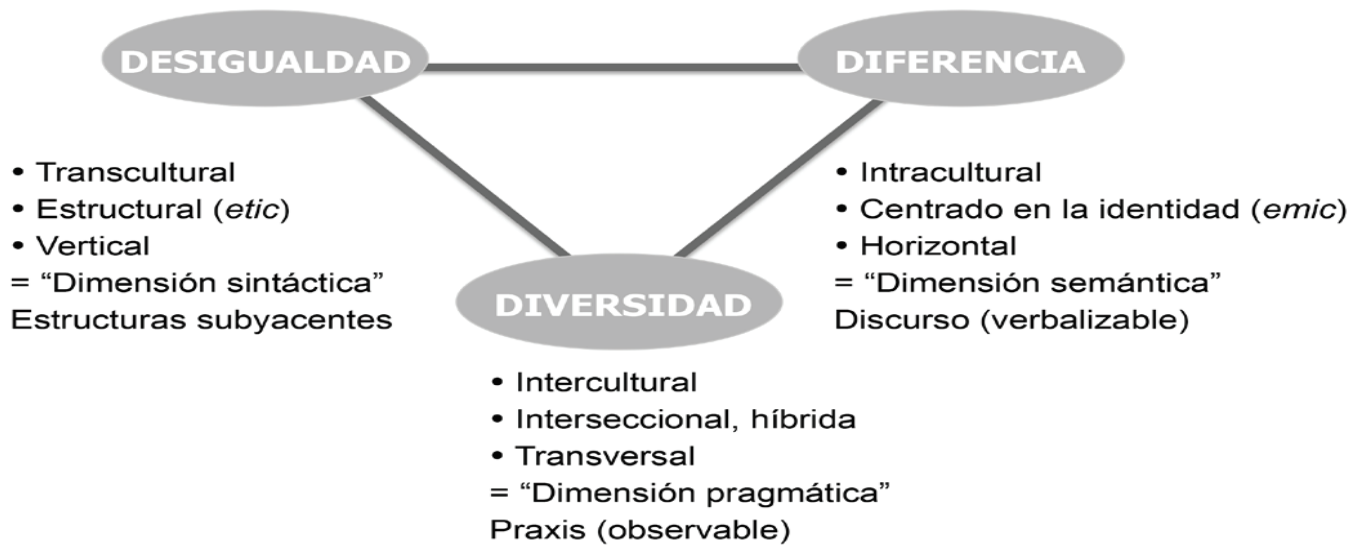

Figura 2 - Desigualdad, diferencia y diversidad en los estudios interculturales

Fonte: Guilherme e Dietz (2014)

O eixo da desigualdade centra-se em uma análise vertical das estruturas sociais e de gênero. Este paradigma versa sobre questões assimilacionistas que identificam nos sujeitos carências como fonte de desigualdade; possui forte viés monolíngue e monocultural.

O eixo da diferença, em contrapartida, está fortemente vinculado aos novos movimentos sociais e de política identitária. Eixo horizontal, buscando a promoção da diversidade nos mais diferentes sentidos.

Por fim, o eixo da diversidade está pautado através da sua crítica ao monoculturalismo assimilacionista e do multiculturalismo essencializador. Neste eixo, o caráter plural, 
contigente e híbrido é o foco, pois parte de experiências de identidades múltiplas, diversas e heterogêneas.

Para os autores (2014), a análise desta tríade nos permite ver a interculturalidade e a diversidade como fenômenos complexos e não fixados ao conceito de competência, trazendo implicações diretas ao ensino, não só de línguas, mas em ambientes sociolinguisticamente complexos. Desta forma, os autores defendem um ensino no qual as relações se dão de modo transversal, aproveitando-se dos entre lugares dispostos no linguajear, entre os territórios formados no contexto educacional.

\subsection{Do questionário}

Foram aplicados 61questionários para professores de diferentes escolas e centros de educação municipais de Foz do Iguaçu. Os sujeitos da pesquisa participaram no segundo semestre de 2016 e no primeiro semestre de 2017 de um curso de formação permanente, de 60 horas, para professores da rede municipal de ensino, com o título Pedagogia Intercultural. O objetivo do curso era capacitar professores e professoras na formação intercultural entendida desde a diversidade das culturas, sendo a participação era voluntária. A primeira edição do curso, em 2016, foi realizada na Escola Municipal Adele Zanotto Scalco, e a maioria dos participantes eram de escolas da região (perto da Ponte Tancredo Neves - divisa com Argentina). Já o curso de 2017 foi realizado no Núcleo de Tecnologia do Município, localizado dentro do Parque Tecnológico de Itaipu, e a maioria dos participantes, como era de se esperar, eram de escolas da região (perto da Ponte da Amizade - divisa com o Paraguai). Além disso, todas as escolas identificadas no questionário tinham estudantes de nacionalidades que não a brasileira.

O questionário, sigiloso, era composto de nove perguntas dissertativas e indicação para o nome da escola e formação em nível superior. As perguntas eram as seguintes:

1. Para você, o que é morar na fronteira?

2. Com que frequência você vai para os países vizinhos?

3. Tem amigos/conhecidos/ familiares argentinos e /ou paraguaios?

4. Você conhece ou usa palavras em espanhol ou guarani no seu dia a dia? Quais? E em quais ocasiões?

5. Como você definiria/ descreveria o argentino?

6. Como você definiria/ descreveria o paraguaio?

7. Você acha que a maioria dos paraguaios são como você descreveu?

8. Você acha que a maioria dos paraguaios são como você descreveu?

9. Você tem alunos de outras nacionalidades ou que falam uma língua diferente do português na sala de aula? Como lida com isso? 
Da formação dos participantes, a 42 deles haviam cursado - somente dois estão cursando - Pedagogia ou Normal Superior. O restante tinha formação em Letras, História, Educação Física e Psicologia.

Em seguida apresentaremos uma breve análise de algumas respostas que nos chamaram a atenção.

\subsection{Da análise}

Para melhor compreensão, dividiremos as perguntas feitas em três blocos:

1. Territorialidade (perguntas de $1-4$ )

2. Observar e linguajear (perguntas de 5-8)

3. Práxis (pergunta 9)

\subsubsection{Territorialidade}

O foco neste bloco foi a palavra privilégio. Todos os sujeitos comentaram sobre o privilégio de se habitar na fronteira devido as oportunidades e pela diversidade presente nela. Mas, em contrapartida, pouco se deslocam aos países vizinhos, sendo o máximo da frequência citada, duas vezes ao mês (por dois sujeitos). Logo, esta diversidade citada é receptiva, ou seja, eles a percebem/ recebem através do discurso da mídia, que aborda a cidade como tendo diversas culturas e como sendo um dos destinos mais procurados do mundo. Eles ouvem este discurso, internalizam e o reproduzem, naturalizando-o, destacando somente o lado positivo de se viver em um ambiente multicultural.

Assim percebemos que não há deslocamento e nem estranhamento ou conflito destes sujeitos, pois essa diversidade somente é observada a partir do próprio lócus enunciativo, uma das respostas dos sujeitos diz claramente que morar na fronteira "é conviver em harmonia com outras culturas e costumes como se fosse nossa própria casa." Com isso, compreendemos que esse privilégio citado corresponde a uma passagem pelo território do sujeito e o não conhecimento, podemos até chamar de invisibilização, dos outros territórios, tal perspectiva pode ser observada na resposta das outras perguntas do bloco ,do mesmo sujeito da citação anterior, no qual o sujeito informa que tem muitos paraguaios e/ou argentinos e que vai com certa frequência ao Paraguai, mas afirma que não conhece e não utiliza palavras em espanhol ou guarani e que os amigos falam "o portunhol e eu o português".

Tal informação pode ser corroborada quando vemos que praticamente 57 sujeitos têm parentes e/ou amigos no Paraguai ou na Argentina, mas se compararmos com a frequência que estes mesmos sujeitos vão aos países vizinhos, podemos concluir que se há contato entre 
familiares e amigos ou é esporádico ou é realizado dentro do seu próprio território, além disso, raramente esse contato é feito na língua adicional, somente 4 sujeitos afirmaram que conversam em espanhol (nenhum em guarani) com outras pessoas.

Levando em consideração que as identidades sociais são desenvolvidas dentro de territórios, pode-se conjecturar que as identidades desses professores são localizadas incluindo certos critérios: o do privilégio de se habitar em um espaço multicultural, no qual eu não preciso me deslocar e me adaptar culturalmente para entrar em contato com o outro. Salientamos aqui que não há nenhum desconforto linguístico para tanto e muito menos confronto, e havendo pode-se facilmente retornar ao ambiente de conforto inicial (do privilégio, da normalidade).

\subsubsection{Observar e linguajear}

Neste bloco fizemos a seguinte divisão: (a) comentários majoritariamente positivo, (b) comentários majoritariamente negativos e (c) comentários neutros. Em (c) compreendemos como sendo posições opostas as respostas dadas anteriormente, isto é, no questionário o sujeito responde que descreve o argentino arrogante (pergunta 5), mas que acredita que nem todo argentino seja assim (pergunta 7), ou respostas claramente didáticas. Desta maneira pudemos obter o seguinte resultado:

(a) 22 respostas

(b) 14 respostas

(c) 25 respostas

Entre as respostas elencadas no grupo (a) temos as seguintes: "um povo amigo e gentill", "muito determinado, defensor de seus valores e cultura", "povo muito religioso", "pessoas educadas, prestativas, sempre fui bem tratada quando estive na Argentina.”.

Já em (b) temos respostas como "eles não são acessíveis", "como turistas, no Brasil, são educados e alegres. Como autoridades, no seu país, são mal educados e abusam do poder", "arrogante, se acham melhor que nós brasileiros. Um pouco frios na receptividade", "não confiável. Talvez porque os produtos que vamos comprar lá eles querem nos enganar, coisas assim", "o paraguaio é individualista".

Em (c) aparecem as seguintes questões: "fechados e mais chatos", mas não acredita que todos os argentinos sejam assim. Outro diz que "são pessoas mais fechadas, não demonstram muita afetividade", mas informa que esse contato foi somente com pessoas que conviveu. Outra informa que são "um povo alegre e esforçado", mas acredita que a maioria dos argentinos não seja assim. Como respostas didáticas, elencamos a seguinte resposta 
"pessoa nascida na Argentina. Adoram o carnaval brasileiro. Migram no verão para as praias do litoral de Santa Catarina. Geram caos no trânsito da nossa cidade. Gostam de vir fazer compras no nosso comércio local." Outra resposta que foi classificada como didática são respostas no estilo "são pessoas normais", "são pessoas com sotaque estrangeiro.".

As visões apresentadas são diversas, mas podemos observar a predominância de levantamento de aspectos positivos frente ao paraguaio e argentino, mesmo quando a princípio há uma resposta negativa, essa é contradita em respostas posteriores. Concordamos aqui com Maturana (2001, p. 169), quando diz que "o mais óbvio e o mais próximo são sempre mais difíceis de perceber", aqui o contato frequente e constante faz com que generalizações e características vagas estejam presentes no discurso. Além disso, apesar do segurança do anonimato do questionário, não podemos esquecer que eles responderam as perguntas conscientizados sobre a pesquisa em questão, podendo então dar respostas que a pesquisadora gostaria de ler.

Percebemos, desta forma, que tal como afirma Maturana (2001), a constituição desses sujeitos se dá pelo observar e pela interação com o outro. Como vimos em respostas anteriores, o contato com argentinos e paraguaios não é intenso e/ou proposital, fazendo com que o conhecimento destes também seja minimizado e generalizado.

\subsubsection{Práxis}

Neste bloco podemos observar a inexistencia da presença de estudantes de outras nacionalidades. Dos sujeitos da pesquisa somente 5 responderam que não tem/ tiveram estudantes de outras nacionalidades. Todos os outros que têm estudantes estrangeiros responderam que os tratam "normalmente", não fazendo distinção entre os estudantes brasileiros. Muitos deles salientam a dificuldade linguística desses alunos na língua portuguesa - afinal, eles estão sendo alfabetizados e/ou ensinados em uma língua que não é a língua materna deles - e de características como vergonha em falar ou ler em voz alta. Uma das profesores informa que não tem aluno de outra nacionalidade no momento, "mas já tive, temos que lidar normalmente." Já outra informa que "tenho dificuldade em me comunicar, mas como conheço um pouco de español, o básico, conseguirmos nos entender”.

Invisibilizar estes alunos e tentar tratá-los como iguais só enfatiza as dificuldades de aprendizagem e salientam as diferenças entre os educandos. Não respeitá-los como sujeitos, construídos em sua própria linguagem é minizar seus hábitos, valores e costumes e sobrepujar o nacional. A questão da linguagem pode ser observada no trecho a seguir de uma das 
professoras participantes da pesquisa, no qual ela informa que "precisamos criar meios para que este aluno integre-se o mais rápido com o grupo e com a nossa língua.”

\section{Conclusões}

Por fim, sugerimos que uma pedagogia voltada às relações interculturais linguajeadas sejam premissa básica de uma educação engajada neste território plural e diverso. Aqui nesta pesquisa, o foco foi em relação ao outro estrangeiro, de nacionalidade diferente da minha, mas defendemos uma abordagem intercultural no qual seja necessário e premente celebrar a diversidade em todas as suas formas: sociais, étnicas, religiosas, de gênero, etc.

É preciso que toda a comunidade escolar se mobilize para compreender e ver o outro na sua plenitude e com ele apre(e)nder e se modificar. Por isso, concordamos com bell hooks (2017, p.35)

\footnotetext{
Quando a educação é a prática da liberdade, os alunos não são os únicos chamados a partilhar, a confessar. A pedagogia engajada não busca simplesmente fortalecer e capacitar os alunos. Toda sala de aula em que for aplicado o modelo holístico de aprendizado será também um local de crescimento para o professor, que será fortalecido e capacitado por esse processo.
}

Todavia sabemos do árduo caminho que é fazer da educação uma via na qual docentes e discentes aprendem conjuntamente, a partir da abertura intelectual e se regozijando pela e na diversidade.

\section{Referências}

GOES FILHO, Synesio Sampaio. As fronteiras do Brasil. Brasília: FUNAG, 2013.

GUILHERME, Manuela; DIETZ, Gunther. Diferencia en la diversidad: perspectivas múltiples de complejidades conceptuales multi, inter y transculturales. Estudios sobre las Culturas Contemporáneas, vol. XX, núm. 40, 2014, pp. 13-36.

FOUCAULT, Michel. Microfísica do poder. Rio de Janeiro: Edições Graal, 1979.

HAESBART, Rogério. Identidades territoriais. In: ROSENDHAL, Z. e CORRÊA, R. Manifestações da cultura no espaço. Rio de Janeiro: EdUERJ, 1999.

hooks, bell. Ensinando a transgredir. A educação como prática da liberdade. São Paulo: Martins Fontes, 2017.

JORDÃO, C. M. ILA - ILF - ILE - ILG: Quem dá conta? In: Revista Brasileira de Linguística Aplicada, Belo Horizonte, v.14, n.1, p.13-40, 2014.

MATURANA, H. Cognição, ciência e vida cotidiana. 1. reimpressão. Belo Horizonte: Ed. Da UFMG, 2001. 
A ontologia da realidade. 3. reimpressão. Belo Horizonte: Ed. Da UFMG, 2002.

MATURANA, H. \& VERDEN-ZÖLLER, G. Amar $e$ brincar: fundamentos esquecidos do humano do patriarcado à democracia. São Paulo: Palas Athena, 2011.

OLIVEIRA, Nara. Foz do Iguaçu intercultural. Cotidianos e narrativas da alteridade. Foz do Iguaçu: Epígrafe, 2012.

PMFI. Foz do Iguaçu é o $3^{\circ}$ destino mais visitado por turistas estrangeiros no país. Disponível em: http://www.pmfi.pr.gov.br/noticia/?idNoticia=41288 Acesso em 16 de julho de 2017.

Portaria 213, de 19 de julho de 2016. Ministério da Integração Nacional. Estabelece o conceito de "cidades-gêmeas" nacionais, os critérios adotados para essa definição e lista todas as cidades brasileiras por estado que se enquadram nesta condição. Brasília: Diário Oficial da União, seção 1, n.138, quarta-feira, 20 de julho de 2016.

VAZ N. M. O linguagear é o modo de vida que nos tornou humanos. In: Ciência e Cultura, vol. 60, nº spe 1, São Paulo, jul - 2008. 